MICROPOROUS AND MESOPOROUS MATERIALS (ISSN: 1387-1811) 190: pp. 46-53. (2014)

DOI: 10.1016/j.micromeso.2014.01.021

\title{
Hydroconversion of acetic acid over carbon aerogel supported molybdenum
} catalyst

\section{Dániel Ábrahám¹, Balázs Nagy¹, Gábor Dobos², János Madarász ${ }^{3}$, György Onyestyák $^{4}$, Mikhail V. Trenikhin ${ }^{5}$, Krisztina László ${ }^{1}$}

${ }^{1}$ Department of Physical Chemistry and Materials Science, Budapest University of Technology and Economics, H-1521 Budapest, Hungary

${ }^{2}$ Department of Atomic Physics, Budapest University of Technology and Economics, H-1521 Budapest, Hungary

${ }^{3}$ Institute of General and Analytical Chemistry, Budapest University of Technology and Economics, H-1521 Budapest, Hungary

${ }^{4}$ Institute of Materials and Environmental Chemistry, Research Centre for Natural Sciences, Hungarian Academy of Sciences, Budapest, Hungary

5 Institute of Hydrocarbon Processing, Omsk Scientific Center, Siberian Branch, Russian Academy of Sciences, Omsk, 634055 Russia

*Corresponding author. Department of Physical Chemistry and Materials Science, Budapest University of Technology and Economics, H-1521 Budapest, Hungary; Tel: +36-1-4631893; E-mail: klaszlo@mail.bme.hu (Krisztina László) 


\begin{abstract}
High surface area carbon aerogels with increasing molybdenum content were obtained by carbonization of resorcinol-formaldehyde polymer aerogels after incipient wetness impregnation (IWI). The Mo(VI) form of the impregnant was converted into different molybdenum species during the heat treatment, resulting in samples with substantially different surface and bulk compositions. The samples were tested in the hydroconversion reaction of acetic acid, a model biomass. The reaction pathways and the product distribution were governed by the accessibility of the carbon surface as well as by the amount and form of Mo. The highest selectivity for ethanol was $16 \%$, when $85 \%$ of the acetic acid was converted. Post-catalyst analysis of the aerogels revealed that their morphology and chemistry changed substantially during the redox processes. The products of each of the three potential pathways (hydrogenolysis, ketonization and consecutive reduction) oxidized the surface even in the reductive hydrogen flow.
\end{abstract}

Keywords: porous carbon support, molybdenum, biomass conversion, XPS, catalysis

\title{
1. Introduction
}

Concern about critical metals has oriented attention to their substitution in several fields of application, including heterogeneous catalysis. Owing to their similar electronic structure, transition metal carbides can potentially substitute noble metals in catalytic processes $[1,2]$. The catalytic activity of these carbides is attributed to the carbon atoms, which constitute up to $50 \%$ of the crystalline structure. They increase the length of the metal-metal bonds, thus increasing the electron density of the d orbitals at the Fermi level of the transition metal atom [3]. The electronic structure at the Fermi 
edge is responsible, e.g., for the enhanced catalytic activity of a carburized Mo surface, since these electrons participate directly in the interaction with the adatoms [4].

Several compounds of molybdenum exhibit a catalytic effect. Sinfelt and Yates were the first to draw attention to the catalytic activity of molybdenum carbide [5]. Nowadays $\mathrm{Mo}_{2} \mathrm{C}$ catalysts have aroused renewed interest [6]. The properties of $\mathrm{Mo}_{2} \mathrm{C}$ are similar to those of the platinum-group metals $(\mathrm{Ru}, \mathrm{Rh}, \mathrm{Pd}, \mathrm{Os}, \mathrm{Ir}, \mathrm{Pt})$, and may therefore replace them in several cases $[5,7-10]$. Nevertheless, in the dehydrogenation of alkenes, $\mathrm{Mo}_{2} \mathrm{C}$ is a milder catalyst than those metals, and the longer lifetime of the $\mathrm{C}_{\mathrm{x}} \mathrm{H}_{\mathrm{y}}$ fragments therefore allows them to connect or stabilize. $\mathrm{Mo}_{2} \mathrm{C}$ is less active in cleaving the $\mathrm{C}-\mathrm{C}$ bonds, and consequently cracking reactions are repressed [11]. Furthermore $\mathrm{Mo}_{2} \mathrm{C}$ is also responsible for the decomposition of ethylene to methane, which can be converted to benzene [12]. Wang and co-workers converted methane to benzene on a $\mathrm{MoO}_{3} / \mathrm{ZSM}-5$ catalyst with $100 \%$ selectivity and $10-12 \%$ conversion at $973 \mathrm{~K}$ [13]. The active species is the carbide, which is formed after a rather long induction period, in which carbon is deposited and the oxide is reduced [14]. The potential of molybdenum-carbide catalysts is actively investigated for several applications, e.g., in electrochemical capacitors [15], fuel cells [16, 17], hydrodesulphurization reactions [18], dehydrogenation reactions [19], Fischer-Tropsch synthesis [20], etc.

During the past decade, molybdenum oxide catalysts have been extensively investigated. The dispersion of Mo oxide, its oxidation state and structure strongly depend on the support material [21]. Alumina and silica supported Mo catalysts are technologically the most important, and the most widely studied. Several factors influence the phase structure of the molybdenum: the preparation method of the oxide 
support and the catalyst, as well as the Mo loading [22]. Interest in the study of Mo is justified by its wide range of catalytic applications, including hydro-desulfurization [23], metathesis [24] or oxidation [25]. The great flexibility of supported molybdenum catalysts is related to the different molecular structures that molybdenum species can thereby simultaneously possess, and to the ability of the Mo atoms to form various oxidation states, depending on the pre-treatment and the reaction [22]. Kim et al. [26] extensively studied the molar structures and reactivity of supported Mo oxides. Mo oxide catalysts can be used for the partial oxidation of toluene. Nag et al. found that the activity of the catalyst is higher than that of molybdate salts, which in turn are more active than crystalline $\mathrm{MoO}_{3}[27]$.

Carbon aerogels (CAs) have been used as catalyst supports since their "discovery" at the end of the 1980s [28]. One of the pioneering studies was the isomerization reaction of but-1-ene with Cr-, Mo- and W-oxide doped carbon aerogel catalysts. The two major products obtained were isobutene and trans-2-butene [29]. The high surface area of the CA is coupled with a network of wide pores, providing ideal conditions both for transport and surface reactions. CAs are obtained from organic xeroor aerogels by thermal treatment. The structure of the developing wet gel can be tuned by the synthesis conditions of the sol-gel polycondensation reaction in the preparation (choice of starting monomers, of the solvent or of the catalyst, stoichiometry, concentrations, temperature, time, etc.) [30 - 35]. The pore structure can be preserved by careful supercritical drying $[36,37]$. In the final thermal treatment, microporosity can be enhanced at the same time as conserving the wider pore network [38, 39].

An additional advantage of the sol-gel synthesis route is that metal atoms can be relatively easily incorporated at several different stages. The strategies employed are (i) 
dissolving the metal precursor in the monomer solution, (ii) ion exchange on the wet polymer gel [40], and (iii) impregnation of the dry polymer or carbon gel. When (i) is employed the dissolved metal precursors modify the polymerization conditions, which significantly influences the properties of the resulting gel [41]. Scanning electron microscope (SEM) images confirm the relationship between the $\mathrm{pH}$ of the reaction mixture and the size of the particles formed [42]. In the post-impregnation technique the added metal also affects the pore structure through pore blocking [43]. In addition to doping with $\mathrm{Na}, \mathrm{Mg}, \mathrm{K}$ [44], Ti [45, 46], Cr [47], Fe, Co, Ni [42], Cu [40, 42, 48, 49], Zr [50], Ru [51], Pd, Ag [34], W [47] and Pt [34], studies on Mo-doped carbon aerogels have also been reported [47].

Several biomass conversion pathways yield carboxylic acids as intermediates. The bio-oil obtained from pyrolysis of lignocelluloses also contains lower carboxylic acids and aldehydes in high concentrations. The selective catalytic conversion of acetic acid and fatty acids yields alcohols, ethers and esters, all of which are important materials for the chemical and fuel industries [52]. Recently it was found that Mo doped carbon aerogels exhibit catalytic activity in the reductive hydrogenation of acetic acid, which can be considered as a model compound for such systems [53].

In this paper we report a systematic study on the catalytic hydroconversion of acetic acid in the presence of carbon aerogel catalysts having different Mo-content. The effect of molybdenum content, its influence on the reaction mechanism and the properties of both the pristine and the used catalysts are investigated.

\section{Experimental}

\subsection{Materials}


Polymer aerogels were prepared by the aqueous polycondensation reaction of resorcinol (R) and formaldehyde (F) by the method of Pekala [28] modified by Lin and Ritter [30]. Briefly, resorcinol (99\%, Merck) (R), formaldehyde (37\% in water, Merck) (F) and sodium carbonate (99\%, Merck) (C) were dissolved in distilled water with molar ratios $\mathrm{R} / \mathrm{F}=0.5$ and $\mathrm{R} / \mathrm{C}=50$. The overall concentration was $5 \mathrm{w} / \mathrm{w} \%$. The initial $\mathrm{pH}$ of the solution was adjusted to $\mathrm{pH} 6.0$ with dilute $\mathrm{HNO}_{3}$ (Merck). The RF sol was kept at $358 \mathrm{~K}$ for one week to complete the gelation. After solvent exchange, the hydrogels were dried with supercritical $\mathrm{CO}_{2}$. Detailed descriptions of the preparation and drying are given elsewhere $[37,54]$.

The incipient wetness impregnation (IWI) technique was used for the impregnation. $4 \mathrm{~mL}$ aqueous ammonium-heptamolybdate-tetrahydrate (AHM) (99\% Merck) solution of 25-200 g/L was added to $1 \mathrm{~g}$ polymer aerogel. The oven dried gel $(383 \mathrm{~K})$ was heat treated in a rotary quartz reactor in dry high purity nitrogen flow at $1173 \mathrm{~K}$ for $1 \mathrm{~h}$. The nomenclature and the expected molybdenum content of the samples are listed in Table 1.

\subsection{Methods}

\subsubsection{Nitrogen adsorption}

Nitrogen adsorption/desorption isotherms were measured at $77 \mathrm{~K}$ by a NOVA 2000e (Quantachrome, USA) volumetric computer-controlled surface analyzer. The samples were outgassed at room temperature. The apparent surface area $S_{\mathrm{BET}}$ was calculated using the Brunauer-Emmett-Teller (BET) model [55]. The total pore volume $\left(V_{\text {tot }}\right)$ was derived from the amount of vapour adsorbed at relative pressure $p / p_{0} \rightarrow 1$, assuming that the pores are filled with liquid adsorbate. The micropore volume $\left(W_{0}\right)$ 
was derived from the Dubinin-Radushkevich (DR) plot [56]. The pore size distribution was computed with the Quenched Solid State Density Functional Theory (QSDFT) using the "slit/cylinder pores QSDFT adsorption branch" kernel [57]. Transformation of the primary adsorption data and pore size analysis were performed with the Quantachrome software (version 10.0).

\subsubsection{X-ray photoelectron spectroscopy (XPS)}

The surface chemical composition of the samples was determined by XPS using $\mathrm{Mg} \mathrm{K}_{\alpha} \mathrm{X}$-rays from an XR3E2 (VG Microtech) twin anode X-ray source and a CLAM2 hemispherical electron energy analyzer. The base pressure of the analysis chamber was about $2 \cdot 10^{-9}$ mbar. The $\mathrm{Mg} \mathrm{K}$ 至adiation $(1253.6 \mathrm{eV})$ was used without a monochromator. Wide scan spectra in the binding energy range $1100-0 \mathrm{eV}$ were recorded with an energy bandpass of $50 \mathrm{eV}$ for all samples. The high resolution spectra of the $\mathrm{C} 1 \mathrm{~s}, \mathrm{O} 1 \mathrm{~s}$ and the Mo3d signals were recorded with an energy bandpass of $20 \mathrm{eV}$. A set of mixed Gaussian-Lorentzian functions was fitted to the peaks of each spectrum after subtracting Shirley-type backgrounds using CasaXPS (2.3.15. version). The components were identified on the basis of data from refs [58, 59].

\subsubsection{X-ray diffraction (XRD)}

The molybdenum-carbides were identified by X-ray diffraction. The XRD patterns were obtained in the range $2 \Theta=4-84^{\circ}$ with an X'Pert Pro MPD (PANalytical $\mathrm{Bv}$ The Netherlands) apparatus using an X'celerator type detector and $\mathrm{Cu} \mathrm{K}_{\alpha}$ radiation with a Ni filter foil $(\lambda=1.5408 \AA)$. 


\subsection{Catalytic experiments}

The hydroconversion of acetic acid (96\%, Reanal) was studied at 21 bar and 673 $\mathrm{K}$ in a stainless steel high-pressure flow-through reactor. The pressure of the acetic acid and hydrogen were 2 and 19 bar, respectively. $200 \mathrm{mg}$ catalyst was used in the form of synthesized particles of size ca. $1 \times 1 \times 1 \mathrm{~mm}^{3}$. A blank test was run under the same conditions in a quartz-filled reactor. The catalysts were preconditioned for $1 \mathrm{~h}$ in hydrogen flow $(723 \mathrm{~K}, 21$ bar) prior to the catalytic tests. After cooling the reactor to the temperature of our catalytic experiments, acetic acid of the highest space time was added to the gas flow for a time-on-stream of $2 \mathrm{~h}$. (Control experiments proved that this period was enough to stabilize the surface properties of the catalyst.) The conversion isotherms were collected over the catalyst obtained after these procedures. Further details are given elsewhere [52]. The liquid fraction of the product was analyzed at ambient conditions by gas chromatography (Shimadzu 2010, HP-Plot/U capillary column, flame ionization detector, FID). An on-line gas chromatograph (HP 5890, Carboxen 1006 Plot capillary column, thermal conductivity detector, TCD) was used for the analysis of the gaseous reactor effluent.

\section{Results and discussion}

\subsection{Characterisation of the virgin catalyst}

The nitrogen adsorption-desorption isotherms in Figure 1 reveal the influence of impregnation on the pore structure of the molybdenum doped carbon aerogels. As the Mo-content increases with respect to Mo0c, the surface area and both the total and the micropore volumes decrease, except in Mo50c, where all three increase (Table 2). Since blocking of the narrower mesopores reduces the mesopore volume, while blocking of 
the wider pores increases it, the volume of this pore category, defined as $\left(V_{\text {tot }}-W_{0}\right)$, is the least influenced by the added salt. The position of the hysteresis loop, typical for mesoporous systems, shifts to a lower $p / p_{0}$ range in the Mo-doped samples. It is worthwhile to note that this interval is not influenced by the Mo-content. The broadened interval in the Type H2 loop [60] shows that the pores are interconnected, and that they are of different size and shape. In samples Mo100c and Mo200c, the low pressure hysteresis can be attributed to irreversible intercalation within micropores of molecular dimensions [61]. The pore size distribution in the micropore and mesopore range is shown in Figure 2. The high resolution transmission microscopy (HRTEM) image reveals that the molybdenum is finely distributed in the carbon matrix (Figure 3). The surface composition of the samples from XPS analysis is shown in Table 3. The Mo concentration on the surface is lower than the calculated value (Table 1), but increases monotonically with the concentration of the IWI solution. Identification of the Mo species is not always straightforward [59]. Owing to spin - orbit coupling, Mo(VI) in AHM gives a double peak at $232.3 \mathrm{eV}\left(3 \mathrm{~d}_{5 / 2}\right)$ and $235.5 \mathrm{eV}\left(3 \mathrm{~d}_{3 / 2}\right)$. The thermal treatment causes the split of the Mo peaks, i.e., the molybdenum is present in two different chemical states on the surface of the carbon aerogel support (Figure 4, Table 4). The shift in the binding energies indicates that both forms of Mo are in a lower oxidation state than in the parent AHM. The more reduced form appears at binding energies $227.9 \mathrm{eV}\left(3 \mathrm{~d}_{5 / 2}\right)$ and $231.2 \mathrm{eV}\left(3 \mathrm{~d}_{3 / 2}\right)$ and the less reduced form at $232.6 \mathrm{eV}$ $\left(3 \mathrm{~d}_{5 / 2}\right)$ and $235.1 \mathrm{eV}\left(3 \mathrm{~d}_{3 / 2}\right)$. Although the energies of the latter are very close to Mo in the parent AHM [62], it is unlikely that AHM survives the high temperature treatment but is rather converted into native Mo oxide [63]. The lower energy can be assigned either as metallic molybdenum or as carbides formed on the carbon surface. 
The absence of a carbide peak in the $\mathrm{C} 1$ s envelope means that this more reduced state corresponds to metallic Mo [64] (Table 5). The metallic Mo forms in the reaction between the Mo species and the carbon matrix. The more oxidized form develops during the thermal decomposition of AHM [65] and the oxidation of metallic Mo. The surface concentration of the native oxide form is practically constant, while that of the metallic form gradually increases with increasing impregnation; i.e., a native Mo oxide layer is formed on the surface of the thickening metallic Mo layer.

The surface and the bulk compositions of the doped samples are substantially different. On the surface, Mo is either in the metallic or the oxidized state, while in the bulk it forms various crystalline carbides. XRD studies reveal the presence of microcrystalline $\eta-\mathrm{Mo}_{6} \mathrm{C}_{4}[67]$ and crystalline $\alpha-\mathrm{Mo}_{2} \mathrm{C}$ phases [58] in the amorphous carbon carrier (Figure 5, upper curves). These results were also confirmed by HRTEM/SAED observations [53].

\subsection{Catalysis test}

Figure 6 summarizes the distribution of products formed during catalytic hydrogenation. The results are displayed as stacked area graphs: the concentration of the given product is represented by the area between two neighbouring curves [52, 69]. The uppermost line therefore also gives the overall conversion of the acetic acid. Its highest point is considered as the maximum conversion $\eta_{\max }$. The catalytic performance varies as the reaction progresses and is clearly influenced by the Mo content. The catalytic hydroconversion of acetic acid takes place with a complex mechanism (Figure 7). Three well separable pathways can be distinguished: (I) hydrogenolysis yielding carbon monoxide and methane; (II) ketonization producing carbon dioxide and acetone; (III) 
reduction of acetic acid resulting in acetaldehyde and ethanol [52]. To compare the catalysts, the selectivity of ethanol production $\left(S_{\mathrm{EtOH}}\right)$, the initial rate of acetic acid conversion $\left(r_{\mathrm{AcOH}}\right)$ and the selectivity of the different reaction pathways at the highest space time $\left(S_{\mathrm{I}-\mathrm{III}}\right)$ were calculated. $S_{\mathrm{EtOH}}=\frac{c_{\mathrm{EtOH}}}{\eta}$, where $c_{\mathrm{EtOH}}$ is the maximum concentration of ethanol and $\eta$ is the corresponding conversion of the acetic acid. The initial rate of acetic acid consumption is given by the slope of the initial section of the overall conversion. The selectivity of the pathways $J=$ I, II or III was defined as $S_{J}=\frac{\sum c_{i, J}}{\eta}$ where $\sum c_{i, J}$ is the overall concentration of the products $(i)$ obtained in the relevant pathway (Table 6).

Even the undoped carbon exhibited catalytic effect (Figure 6a). The products (carbon-monoxide and methane, 12-12 mol\%) indicate that the reaction path is hydrogenolysis (I). The O-containing surface functional groups (Tables 3-5) promote cleavage of the $\mathrm{C}-\mathrm{C}$ bonds in the acetic acid, and hence the formation of carbonmonoxide and methane. Molybdenum impregnation significantly changes the mechanism of the catalytic reaction. At low space time methane and carbon-monoxide were detected over Mo25c (Figure 6b). However, at space time $>0.17$ the products of the hydrogenolysis reaction disappear. Formation of carbon dioxide and acetone points to the ketonization mechanism (II). The ratio of oxidized/metallic forms $(\mathrm{B}+\mathrm{C}+\mathrm{D}) / \mathrm{A}$ (from Table 4) of molybdenum is the highest on the surface of this sample (2.8), which may be the reason for the dominance of the ketonization process. (This reaction, catalyzed by various metal oxides ( $\mathrm{Si}, \mathrm{Ti}, \mathrm{Al})$, is used in acetone production [70]). The increasing concentration of the evolving acetone and carbon dioxide enhances their sorption on the active sites. This leads to blocking of the surface sites and a decline in catalytic activity. 
On the surface of Mo50c the ratio of oxidized/reduced molybdenum is only 1.5: acetone formation is therefore limited (Figure 6c). Concurrently the amount of carbon dioxide also decreases. The consecutive reduction of acetic acid through pathway III yields acetaldehyde and ethanol. Esterization of the latter with acetic acid yields ethyl acetate. Due to the dehydration of ethanol, however, ethylene is also produced and, in the presence of hydrogen, is converted forthwith to ethane. The hydrogenolysis that is also taking place results in a limited amount of methane and carbon monoxide. On sample Mo100c the reaction mechanism is similar to that of Mo50c due to the similar oxidized/reduced Mo ratio (1.4). The total conversion is lower, but the maximum selectivity of ethanol is higher (Table 6). Over the Mo200c sample, where the ratio of oxidized/reduced Mo is lowest (0.3), hydrogenolysis is totally suppressed. Practically, only the consecutive reduction of acetic acid takes place, yielding acetaldehyde and ethanol. Ethyl acetate and ethane are produced in the successive reactions. The conversion and the selectivity of ethanol were the highest for this sample.

It can be concluded that with increasing molybdenum content the ratio of oxidized/reduced forms of Mo decreases. The reactions that cleave the $\mathrm{C}-\mathrm{C}$ bonds and produce ketonization are therefore suppressed, increasing selectivity for the more valuable products, including ethanol. Both the total conversion and the initial rate of acetic acid consumption increase. The mechanism of the catalytic reaction shifts from hydrogenolysis (I) to the reduction (III), as seen in Figure 7.

\subsection{Post catalytic characterization}

The post-catalytic analysis of the carbon aerogels shows that both the morphology and the chemistry of the catalyst undergo severe changes when exposed to 
the redox processes. According to Figures $1-2$ and the data in Table 2, the pore structure is modified in a complex way: the interaction with hydrogen and the products of the various catalytic processes lead to chemical reactions, activation, pore filling, etc., but the mesopore region is not affected. Figure 1a reveals that the hydrogenolysis itself slightly reduces the surface area and the pore volume in the Mo-free sample. A similar trend was observed with Mo25c, where the Mo-content is the lowest. Sample Mo50c is outstanding, as increased porosity was detected after the catalysis. It is notable that the limits of the hysteresis loops do not change, except in the case of the low pressure hysteresis that appears in the high Mo-content samples (Mo100c and Mo200c). Another indication of surface reactions is the variation in elemental composition (Tables $3,4,5)$. The reduction in carbon content could be the sign of burn-off, also catalyzed by the Mo species present (Table 3). The elemental composition of the post-catalysis Mo50c and Mo100c samples confirms the similarity of the hydroconversion pathways over these two catalysts.

Table 3 clearly shows the enhancement of the surface O/C ratio. Inspection of the last column of Table 5, however, which gives the ratio of the various O-containing carbon groups on the surface, shows that a significant part of the oxygen is bonded to the molybdenum. The change in the distribution of the various $\mathrm{C} 1 \mathrm{~s}$ species is not significant. It is noteworthy that, like in the fresh catalyst, molybdenum carbide was not detected on the surface of the used catalysts.

The Mo is also exposed to chemical reactions. The evolution of the surface Mo species is clearly demonstrated (Figure 8). The most striking feature is the further splitting of the peaks into four different Mo species. A slight reduction occurs in the concentration of metallic Mo (form A), while that of the native oxide increases. The 
new forms B and C (Table 4) are attributed to $\mathrm{Mo}(\mathrm{IV})$ and $\mathrm{Mo}(\mathrm{V})$ forms, but their further distinction is not possible due to the strong overlap [59]. For Mo25c, Mo50c, Mo100c and Mo200c, the ratio of the oxidized/reduced Mo species, i.e., (B+C+D)/A (Table 4), rose to $\sim 10, \sim 9, \sim 4.5$ and $\sim 1$, respectively. The increased contribution of the oxidized Mo species as well as the higher oxygen content of the post-catalysis surfaces demonstrate that the products of all three pathways were able to oxidize the surface, even in the reductive hydrogen flow. The carbides were still present in the bulk (Figure 5). Nevertheless, it is possible that part of these carbides could be converted to volatile oxides or suboxides, which could evaporate or segregate to the surface, thus increasing the concentration of the oxidized form(s) on the surface.

\section{Conclusions}

High surface area carbon aerogels with increasing molybdenum content have been prepared by incipient wetness impregnation (IWI) of the resorcinol-formaldehyde polymer aerogel. The samples obtained after high temperature heat treatment in inert atmosphere contained the Mo in highly dispersed form. The surface and the bulk compositions of the doped samples however were substantially different. While Mo was in metallic form covered by a thin native oxide layer on the surface, it formed (micro)crystalline $\eta-\mathrm{Mo}_{6} \mathrm{C}_{4}$ and crystalline $\alpha-\mathrm{Mo}_{2} \mathrm{C}$ in the bulk phase. The samples proved to be catalytically effective in the hydrogenation reaction of acetic acid, a widely used model compound of biomass. The typical reaction pathways of the hydroconversion, namely hydrogenolysis, ketonization, and consecutive reduction were governed by the accessibility of the carbon surface as well as by the amount and form of the Mo. Without Mo, hydrogenolysis mainly took place. At the lowest Mo content, 
ketonization was dominant, while in the other three samples consecutive reduction was the most typical mechanism.

The highest selectivity for ethanol was $16 \%$, when $85 \%$ of the acetic acid was converted. The post-catalysis analysis of the catalysts revealed that both their morphology and chemistry underwent severe changes when exposed to the redox processes. The pore structure and the surface area were modified in a complex way, but the mesopore region was hardly influenced. The increased contribution of the oxidized surface Mo species as well as the higher oxygen content of the post-catalysis surfaces showed that the products of all the three pathways were able to oxidize the surface, even in the reductive hydrogen flow.

\section{Acknowledgements}

The support of the Marie Curie International Research Staff Exchange Scheme (grant no. 269267) and TÁMOP-4.2.2.A-11/1/KONV-2012-0043 (ENVIKUT) is gratefully acknowledged. The authors thank Sz. Harnos and Gy. Bosznai for their contributions to the experimental work, and E. Geissler for fruitful discussions.

\section{References}

[1] G. Wu, W.T. Tysoe, Surf. Sci. 397 (1998) 197-208.

[2] J. Wang, M. Castonguay, J. Deng, P.H. McBreen, Surf. Sci. 374 (1997) 197-207.

[3] A.M. Stux, C. Laberty-Robert, K.E. Swider-Lyons, J. of Sol. Stat. Chem. 181 (2008) 2741-2747.

[4] P. Reinke, P. Oelhafen, Surf. Sci. 468 (2000) 203-215. 
[5] J. H. Sinfelt, D.J.C. Yates, Nature Phys. Sci. 229 (1971) 27-28.

[6] S.T. Oyama, Catal. Today 15 (1992) 179-200.

[7] L. Leclercq, M. Provost, H. Pastor, G. Leclercq, J. of Catal. 117 (1989) 384-395.

[8] J.M. Mullet, F.G. Gault, Bull. Soc. Chim. Fr. 2 (1970) 416-421.

[9] R.B. Levy, M. Boudart, Science 181 (1973) 547-549.

[10] R. Guil-López, M.V. Martínez-Huerta, O. Guillén-Villafuerte, M.A. Pena, J.L.G.

Fierro, E. Pastor, Int. J. of Hydrogen Energy 35 (2010) 7881-7888.

[11] F. Solymosi, R. Németh, L. Óvári, L. Egri, J. of Catal. 195 (2000) 316-325.

[12] F. Solymosi, J. Cserényi, A. Szőke, T. Bánsági, A. Oszkó, J. of Catal. 165 (1997) $150-161$.

[13] L. Wang, Tao, M. Xie, G. Xu, J. Huang, Y. Xu, Catal. Lett. 21 (1993) 35-41.

[14] Á. Koós, A. Oszkó, F. Solymosi, Appl. Surf. Sci. 253 (2007) 3022-3028.

[15] T. Morishita, Y. Soneda, H. Hatori, M. Inagaki, Electroch. Acta 52 (2007) 24782484.

[16] S. Ball, A. Hodgkinson, G. Hoogers, S. Maniguet, D. Thompsett, B. Wong; Electrochem. and Sol-State Lett. 5 (2002) 31-34.

[17] P.K. Cheekatamarla, W.J. Thomson, J. of Power Source. 158 (2006) 477-484.

[18] P.D. Costa, C. Potvin, J.-M. Manoli, B. Genin, G. Djéga-Mariadassou, Fuel 83 (2004) 1717-1726.

[19] D.W. Flaherty, S.P. Berglund, C.B. Mullins, J. Catal. 269 (2010) 33-43.

[20] N.V. Dai-Viet, A.A. Adesina, Appl. Catal. A 399 (2011) 221-232.

[21] K.V.R. Chary, K.R. Reddy, G. Kishan, J.W. Niemantsverdriet, G. Mestl, J. Catal 226 (2004) 283-291. 
[22] E.A. El-Sharkawy, A.S. Khder, A.I. Ahmed, Micropor. and Mesopor. Mat. 102 (2007) 128-137.

[23] P. Grange, Catal. Rev. Sci. Eng. 21 (1980) 135-181.

[24] W. Grunert, A.Y. Stakheev, W. Morke, J. Catal. 135 (1992) 269-286.

[25] C. Louis, J.M. Tatibouet, M. Che, J. Catal. 109 (1988) 354-366.

[26] D.S. Kim, K. Segawa, T. Soeya, I.E. Wachs, J. Catal. 136 (1992) 539-553.

[27] N.K. Nag, T. Fransen, P. Mars, J. Catal. 68 (1981) 77-85.

[28] R.W. Pekala, J. of Mater. Sci. 24 (1989) 3221-3227.

[29] F.J. Maldonado-Hódar, C. Moreno-Castilla, J. Rivera-Utrilla, Appl. Cat. A 203 (2000) $151-159$.

[30] C. Lin, J.A. Ritter, Carbon 35 (1997) 1271-1278.

[31] H. Tamon, H. Ishizaka, T. Yamamoto, T. Suzuki, Carbon 37 (1999) 2049-2055.

[32] B. Mathieu, S. Blacher, R. Pirard, J.P. Pirard, B. Sahouli, F. Brouers, J. of NonCryst. Sol. 212 (1997) 250-261.

[33] T. Yamamoto, T. Nishimura, T. Suzuki, H. Tamon, J. of Non-Cryst. Sol. 288 (2001) 46-55.

[34] F.J. Maldonado-Hódar, M.A. Ferro-García, J. Rivera-Utrilla, C. Moreno-Castilla; Carbon 37 (1999) 1199-1205.

[35] H. Tamon, H. Ishizaka, J. of Coll. and Interface Sci. 223 (2000) 305-307.

[36] H. Tamon, H. Ishizaka, M. Mikami, M. Okazaki, Carbon 35 (1997) 791-796.

[37] O. Czakkel, K. Marthi, E. Geissler, K. László, Micropor. and Mesopor. Mater. 86 (2005) 124-133.

[38] C. Moreno-Castilla, F. J. Maldonado-Hodar, Carbon 43 (2005) 455-465. 
[39] O. Czakkel, E. Geissler, I.M. Szilágyi, E. Székely,K. László, J. of Coll. and Interface Sci. 337 (2009) 513-522.

[40] T.F. Baumann, G.A. Fox, J.H. Satcher Jr. N. Yoshizawa, R. Fu, M.S. Dresselhaus, Langmuir 18 (2002) 7073-7076.

[41] B. Nagy, O. Czakkel, K. László, Micropor. and Mesopor. Mater. 185 (2014), 66. [42] F.J. Maldonado-Hódar, C. Moreno-Castilla, A.F. Pérez-Canedas, Micropor. and Mesopor. Mater. 69 (2004) 119-125.

[43] C.D. Saquing, T.T. Cheng, M. Aindow, C. Erkey, J. of Phys. Chem. B 108 (2004) 7716-7722.

[44] M.L. Rojas-Cervates, L. Alonso, J. Díaz-Terán, A.J. López-Peinado, R.M. MartínAranda, V. Gómez-Serrano, Carbon 42 (2004) 1575-1582.

[45] C. Moreno-Castilla, F.J. Maldonado-Hódar, F. Carraso-Marin, E. RodríguezCastellón; Langmuir 18 (2002) 2295-2299.

[46] O. Czakkel, E. Geissler, I.M. Szilágyi, K. László, Nanomat. and the Environ. 1 (2013) 23-30.

[47] C. Moreno-Castilla, F.J. Maldonado-Hódar, J. Rivera-Utrilla, E. RodríguezCastellón, Appl. Catal. A 183 (1999) 345-356.

[48] R. Fu, Y.M. Lin, O. Rabin, G. Dresselhaus, M.S. Dresselhaus J.H. Satcher Jr., T.F. Baumann, J. of Non-Cryst. Sol. 317 (2003) 247-253.

[49] O. Czakkel, E. Geissler, A. Moussaïd, B. Koczka, K. László, Micropor. and Mesopor. Mater. 126 (2009) 213-221.

[50] E. Bekyarova, K. Kaneko, Advanced Mater. 12 (2000) 1625-1628.

[51] M. Miller, B. Dunn, T.D. Tran, R.W. Pekala, J. of the Electrochem. Soc. 144 (1997) 309-311. 
[52] Gy. Onyestyák, Sz. Harnos, A. Kaszonyi, M. Štolcová, D. Kalló. Catal. Comm. 27 (2012) $159-163$.

[53] B. Nagy, D. Ábrahám, G. Dobos, J. Madarász, Gy. Onyestyák, Gy. Sáfrán, E.

Geissler, K. László, Carbon 66 (2014) 210-218

[54] O. Czakkel, E. Székely, B. Koczka, E. Geissler, K. László, Micropor. and Mesopor. Mater. 148 (2012) 34-42.

[55] S. Brunauer, P. Emmett, E. Teller, Journal of American Chemical Society 60 (1938) 309-319.

[56] M.M. Dubinin, L.V. Radushkevich, Proc. Acad. Sci. USSR Phys. Chem. Sect. 55 (1947) 331-337.

[57] G.Y. Gor, M. Thommes, K.A. Cychosz, A.V. Neimark, Carbon 50 (2012) 15831590.

[58] D. Briggs, Surface analysis of polymers by XPS and static SIMS, Cambridge University Press, Cambridge, 1998

[59] G. Dobos, K.V. Josepovits, Á. Böröczki, I.Csányi, Gy. Hárs, Int. J. of Refract. Metals and Hard Mater. 27 (2009) 764-767.

[60] S.J. Gregg, K.S.W. Sing, Adsorption, Surface Area and Porosity, Academic Press, London, 1982

[61] A. Bailey, D.A. Cadenhead, D.H. Davies, D.H. Everett, A.J. Miles, Trans. Faraday Soc. 67 (1971) 231.

[62] L.J. Matienzo, S.O. Grim, Inorg. Chem. 14 (1975) 1014.

[63] Z.M. Hanafi, M.A. Khilla, M.H. Askar, Thermochim. Acta 45 (1981) 221.

[64] T.L. Barr, J. Phys. Chem. 82 (1978) 1801.

[65] C. Thomazeau, V. Martin, P. Afanasiev, App. Cat. A. 199 (2000) 61. 
[66] G. Zhang, S. Sun, D. Yang, J.-P. Dodelet, E. Sacher, Carbon 46 (2008) 196.

[67] K. Yamaura, Q. Huang, M. Akaishi, M.E. Takayama, Phys. Rev. B, Cond. Matt. and Mat. Phys. 74 (2006) 1.

[68] K. Page, L. Jun, R. Savinelli, H.N. Szumila, J. Zhang, J.K. Stalick, T. Proffen, S.L.

Scott, R. Seshadri, Sol. State Sci. 10 (2008) 1499.

[69] Gy. Onyestyák, Sz. Harnos, D. Kalló, Cat. Comm. 16 (2011) 184.

[70] M. Gliński, J. Kijeński, A. Jakubowski, App. Catal. A 128 (1995) 209. 


\section{Tables}

Table 1. The expected Mo load of the carbon aerogel supported catalysts.

\begin{tabular}{l|l|l}
\hline \multirow{2}{*}{ Sample } & $\begin{array}{l}\text { Concentration of } \\
\text { the IWI solution }\end{array}$ & $\begin{array}{l}\text { Expected } \\
\text { molybdenum } \\
\text { content }\end{array}$ \\
\cline { 2 - 3 }$(\mathrm{g} / \mathrm{L})$ & $(\mathrm{w} / \mathrm{w} \%)$ \\
\hline \hline Mo0c & 0 & - \\
\hline Mo25c & 25 & 5 \\
\hline Mo50c & 50 & 11 \\
\hline Mo100c & 100 & 22 \\
\hline Mo200c & 200 & 44
\end{tabular}

Table 2. Data deduced from low temperature $(77 \mathrm{~K})$ nitrogen adsorption measurements before and after the catalysis*

\begin{tabular}{|c|c|c|c|c|c|}
\hline \multirow{2}{*}{ Sample } & & \multirow{2}{*}{\begin{tabular}{|l}
$S_{\text {BET }}$ \\
$\left(\mathrm{m}^{2} / \mathrm{g}\right)$
\end{tabular}} & $V_{t o t}$ & $W_{0}$ & \multirow[t]{2}{*}{$V_{\text {meso }}$} \\
\hline & & & & & \\
\hline \multirow[t]{2}{*}{$\mathrm{MoOc}$} & before & 786 & 2.19 & 0.32 & 1.87 \\
\hline & after & 545 & 1.40 & 0.22 & 1.18 \\
\hline \multirow[t]{2}{*}{ Mo25c } & before & 666 & 0.50 & 0.26 & 0.24 \\
\hline & after & 357 & 0.39 & 0.13 & 0.23 \\
\hline \multirow[t]{2}{*}{ Mo50c } & before & 420 & 0.32 & 0.17 & 0.15 \\
\hline & after & 590 & 0.48 & 0.23 & 0.25 \\
\hline \multirow[t]{2}{*}{ Mo100c } & before & 258 & 0.17 & 0.10 & 0.07 \\
\hline & after & 222 & 0.20 & 0.08 & 0.12 \\
\hline \multirow[t]{2}{*}{ Mo200c } & before & 187 & 0.13 & 0.07 & 0.06 \\
\hline & after & 146 & 0.15 & 0.06 & 0.09 \\
\hline
\end{tabular}

* $S_{\mathrm{BET}}$ : apparent surface area; $V_{t o t}$ : total pore volume; $W_{0}$ : micropore volume from the

DR plot; $V_{\text {meso }}=V_{\text {tot }}-W_{0}$ the mesopore volume 
Table 3. Surface composition of the samples from XPS before and after the catalysis

\begin{tabular}{|c|c|c|c|c|c|}
\hline \multicolumn{2}{|l|}{ Sample } & Mo & $\mathbf{C}$ & $\mathbf{O}$ & \multirow{3}{*}{$\begin{array}{l}\mathbf{O} / \mathrm{C}^{*} \\
0.08\end{array}$} \\
\hline & & \multicolumn{3}{|c|}{ weight \% } & \\
\hline \multirow{2}{*}{$\mathrm{Mo0c}$} & before & 0.0 & 90.8 & 9.2 & \\
\hline & after & 0.0 & 84.9 & 15.1 & 0.13 \\
\hline \multirow{2}{*}{ Mo25c } & before & 13.3 & 73.5 & 13.1 & 0.13 \\
\hline & after & 26.5 & 52.9 & 20.6 & 0.29 \\
\hline \multirow{2}{*}{ Mo50c } & before & 15.1 & 70.8 & 14.1 & 0.15 \\
\hline & after & 43.9 & 29.3 & 26.8 & 0.69 \\
\hline \multirow{2}{*}{ Mo100c } & before & 19.7 & 65.0 & 15.3 & 0.18 \\
\hline & after & 43.5 & 25.6 & 30.9 & 0.91 \\
\hline \multirow{2}{*}{ Mo200c } & before & 28.9 & 57.5 & 13.7 & 0.18 \\
\hline & after & 31.7 & 51.3 & 17.0 & 0.25 \\
\hline
\end{tabular}

* from atomic ratios 
Table 4. The different chemical states of molybdenum before and after catalysis, from the deconvolution of the Mo3d signal *

\begin{tabular}{|c|c|c|c|c|c|c|c|c|c|}
\hline \multicolumn{2}{|l|}{ Sample } & $\mathbf{A}$ & B & $\mathbf{C}$ & $\mathbf{D}$ & $\mathbf{A}$ & B & $\mathbf{C}$ & D \\
\hline & & & weig & ht\% & & & & 7 & \\
\hline \multirow{2}{*}{$\mathrm{MoOc}$} & before & 0.0 & 0.0 & 0.0 & 0.0 & 0.0 & 0.0 & 0.0 & 0.0 \\
\hline & after & 0.0 & 0.0 & 0.0 & 0.0 & 0.0 & 0.0 & 0.0 & 0.0 \\
\hline \multirow{2}{*}{ Mo25c } & before & 3.5 & 0.0 & 0.0 & 9.8 & 26.5 & 0.0 & 0.0 & 73.5 \\
\hline & after & 2.4 & 2.0 & 5.6 & 16.6 & 9.0 & 7.4 & 21.1 & 62.6 \\
\hline \multirow{2}{*}{ Mo50c } & before & 6.1 & 0.0 & 0.0 & 9.0 & 40.7 & 0.0 & 0.0 & 59.3 \\
\hline & after & 4.3 & 1.0 & 7.1 & 31.6 & $\mid 9.7$ & 2.2 & 16.2 & 71.9 \\
\hline \multirow{2}{*}{ Mo100c } & before & 8.1 & 0.0 & 0.0 & 11.6 & 41.1 & 0.0 & 0.0 & 58.9 \\
\hline & after & 7.8 & 4.6 & 6.4 & 24.7 & 17.9 & 10.6 & 14.6 & 56.8 \\
\hline \multirow{2}{*}{ Mo200c } & before & 22.2 & 0.0 & 0.0 & 6.7 & 76.9 & 0.0 & 0.0 & 23.1 \\
\hline & after & 15.1 & 1.6 & 0.0 & 13.0 & 46.4 & 5.0 & 8.8 & 39.8 \\
\hline
\end{tabular}

*A: metallic Mo; B , C: Mo(IV) - Mo(V) intermediate states; D: Mo(VI) and/or native oxide of Mo 
Table 5. The different chemical states of carbon before and after the catalysis, from the deconvolution of the $\mathrm{C} 1 \mathrm{~s}$ signal* [66]

\begin{tabular}{|c|c|c|c|c|c|c|c|c|c|c|c|c|c|c|}
\hline \multicolumn{2}{|l|}{ Sample } & $\mathbf{a}$ & b & c & d & e & $\mathbf{f}$ & $\mathbf{a}$ & $\mathbf{b}$ & c & $d$ & e & $\mathbf{f}$ & $c+d+f$ \\
\hline & & & & weig & ht $\%$ & & & \multicolumn{7}{|c|}{$\%$} \\
\hline \multirow{2}{*}{$\mathrm{MoOc}$} & before & 54.5 & 21.5 & 6.5 & 5.1 & 1.4 & 1.8 & 60.0 & 23.6 & 7.2 & $\overline{5.6}$ & 1.5 & 2.0 & 14.3 \\
\hline & after & 35.2 & 35.9 & 5.9 & 5.5 & 1.9 & 0.6 & 41.4 & 42.3 & 6.9 & 6.4 & 2.3 & 0.7 & 15.6 \\
\hline \multirow{2}{*}{ Mo25c } & before & 46.0 & 12.6 & 6.6 & 3.7 & 2.5 & 2.2 & 62.6 & 17.1 & 8.9 & 5.0 & 3.5 & 2.9 & 17.4 \\
\hline & after & 35.0 & 8.2 & 4.5 & 2.8 & 1.1 & 1.3 & 66.1 & 15.5 & 8.5 & 5.3 & 2.1 & 2.4 & 15.9 \\
\hline \multirow{2}{*}{ Mo50c } & before & 45.8 & 11.8 & 6.1 & 3.8 & 1.5 & 1.9 & 64.6 & 16.7 & 8.6 & 5.4 & 2.1 & 2.6 & 16.1 \\
\hline & after & 20.3 & 4.5 & 2.0 & 1.7 & 0.2 & 0.6 & 69.2 & 15.5 & 6.8 & 5.9 & 0.5 & 2.1 & 13.2 \\
\hline \multirow{2}{*}{ Mo100c } & before & 42.1 & 10.9 & 5.5 & 3.2 & 1.4 & 1.8 & 64.7 & 16.8 & 8.5 & 4.9 & 2.2 & 2.8 & 15.6 \\
\hline & after & 18.8 & 2.8 & 2.2 & 1.7 & 0.1 & 0.0 & 73.6 & 10.8 & 8.5 & 6.7 & 0.4 & 0.0 & 15.6 \\
\hline \multirow{2}{*}{ Mo200c } & before & 39.2 & 8.3 & 4.7 & 3.2 & 0.5 & 1.6 & 68.2 & 14.5 & 8.2 & 5.5 & 0.9 & 2.7 & 14.6 \\
\hline & after & 33.5 & 9.7 & 4.4 & 2.4 & 1.3 & 0.0 & 65.4 & 18.9 & 8.6 & 4.6 & 2.5 & 0.0 & 15.7 \\
\hline
\end{tabular}

*a: delocalized aromatic $\mathrm{sp}^{2}$ structures; b: localized aromatic $\mathrm{sp}^{2}$ structures; c: C-O

bonds; $\mathrm{d}$ : $\mathrm{C}=\mathrm{O}$ bonds; e: carboxylic and ethers; f: $\pi \rightarrow \pi^{*}$ shake-up satellite of aromatic $\mathrm{sp}^{2}$ structures 
Table 6. Comparison of the performance of the catalysts

\begin{tabular}{|c|c|c|c|c|c|c|}
\hline \multirow{2}{*}{ Sample } & $\eta_{\max }^{\mathrm{a}}$ & $S_{\text {EtOH }}{ }^{b}$ & $r_{\mathrm{AcOH}}^{\mathrm{c}}$ & $S_{\mathrm{I}}^{\mathrm{d}}$ & $S_{\text {II }}^{\text {d }}$ & $S_{\text {III }}{ }^{\mathrm{d}}$ \\
\hline & \multicolumn{2}{|c|}{$\%$} & $\mathrm{mmol} /\left(\mathrm{g}_{\text {cat }} \cdot \mathrm{h}\right)$ & \multicolumn{3}{|c|}{$\%$} \\
\hline $\mathrm{MoOc}$ & 55 & 4 & 37 & 69 & 6 & 25 \\
\hline Mo25c & 60 & 3 & 59 & 0 & 87 & 13 \\
\hline Mo50c & 78 & 7 & 59 & 14 & 5 & 81 \\
\hline Mo100c & 73 & 13 & 59 & 16 & 10 & 74 \\
\hline Mo200c & 85 & 16 & 67 & 0 & 5 & 95 \\
\hline
\end{tabular}

${ }^{\mathrm{a}}$ maximum conversion; ${ }^{\mathrm{b}}$ maximum selectivity of ethanol; ${ }^{\mathrm{c}}$ initial rate of acetic acid conversion;

${ }^{d}$ selectivity of (I) hydrogenolysis, (II) ketonization, (III) reduction ; $\mathrm{g}_{\text {cat }}$ means g catalyst 


\section{Figure captions}

Figure 1. Low temperature $(77 \mathrm{~K})$ nitrogen adsorption isotherms of the Mo-doped carbon aerogels before and after catalysis. a: Mo0c; b: Mo25c; c: Mo50c; d: Mo100c; e: Mo200c

Figure 2. Pore size distribution before (a) and after (b) catalysis. 1) Mo0c; 2) Mo25c; 3) Mo50c; 4) Mo100c; 5) Mo200c

Figure 3. High resolution transmission electron microscope images of the Mo100c sample (JEM-2100, JEOL, Japan).

Figure 4. Deconvolution of Mo 3d peaks. a: ammonium-heptamolybdate-tetrahydrate, b: virgin Mo200c.

Figure 5. XRD profiles of the carbon aerogels before (upper curves) and after (lower curves) catalysis. Peaks belonging to the $\alpha$ and $\eta$ forms are assigned. a: Mo0c; b: Mo25c; c: Mo50c; d: Mo100c; e: Mo200c.

Figure 6. Product distribution in the hydroconversion reaction of acetic acid. a: Mo0c; b: Mo25c; c: Mo50c; d: Mo100c; e: Mo200c. The concentration of the given product is represented by the area between two neighbouring curves: 1 . acetic acid; 2 . carbon dioxide; 3. acetone; 4. water; 5. ethyl acetate; 6. acetaldehyde; 7. ethanol; 8. carbon monoxide; 9. methane; 10. ethane

Figure 7. Possible reactions taking place during the hydroconversion of acetic acid.

I: hydrogenolysis; II: ketonization; III: consecutive reduction [52]

Figure 8. Deconvoluted Mo 3d peaks after catalytic reaction from XPS. a: Mo25c, b: Mo50c, c: Mo100c, d: Mo200c 


\section{Figures}

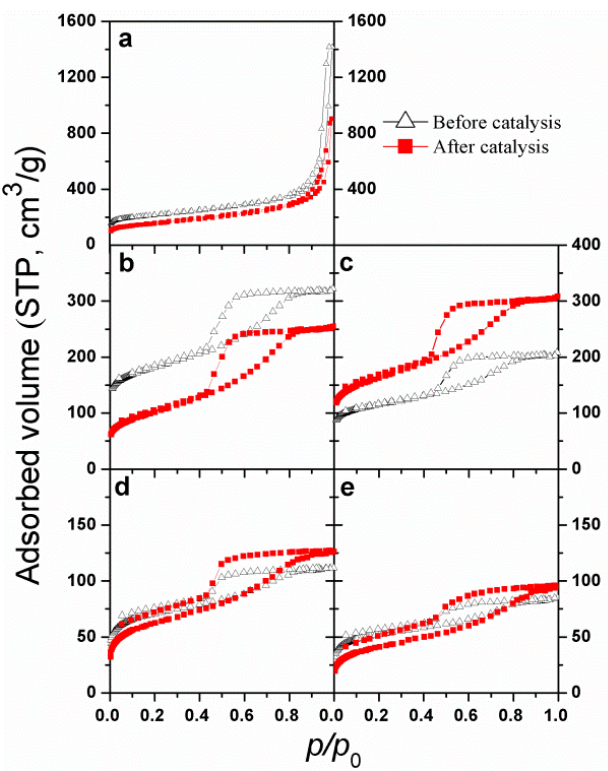

Figure 1

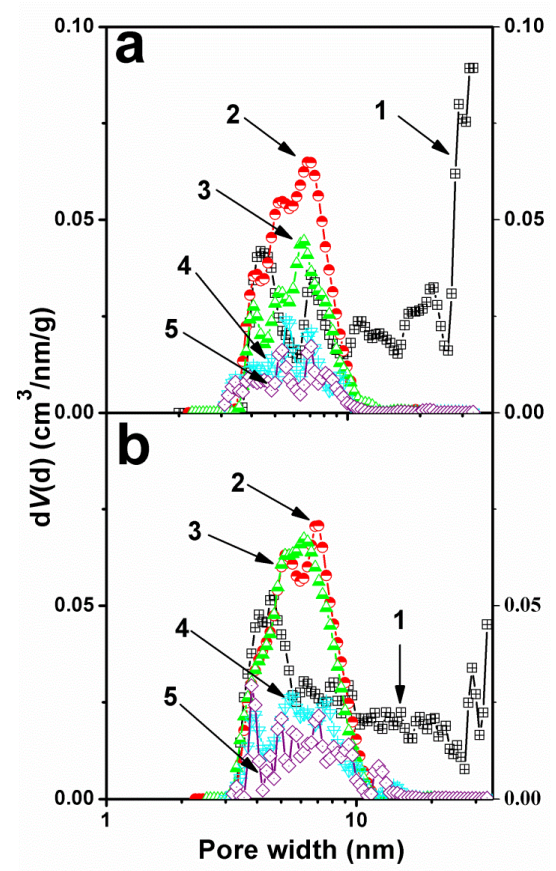

Figure 2. 

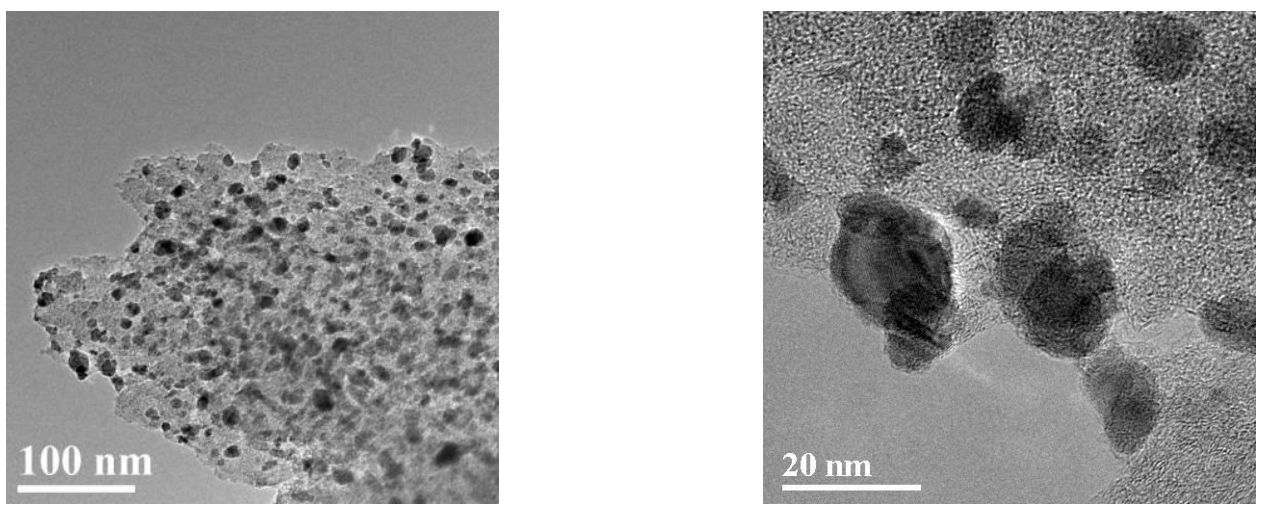

Figure 3 .
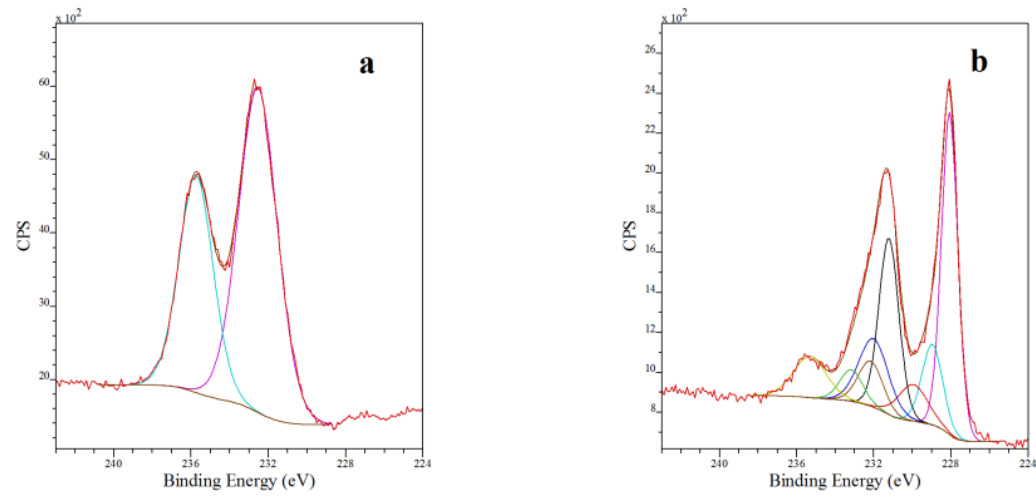

Figure 4.

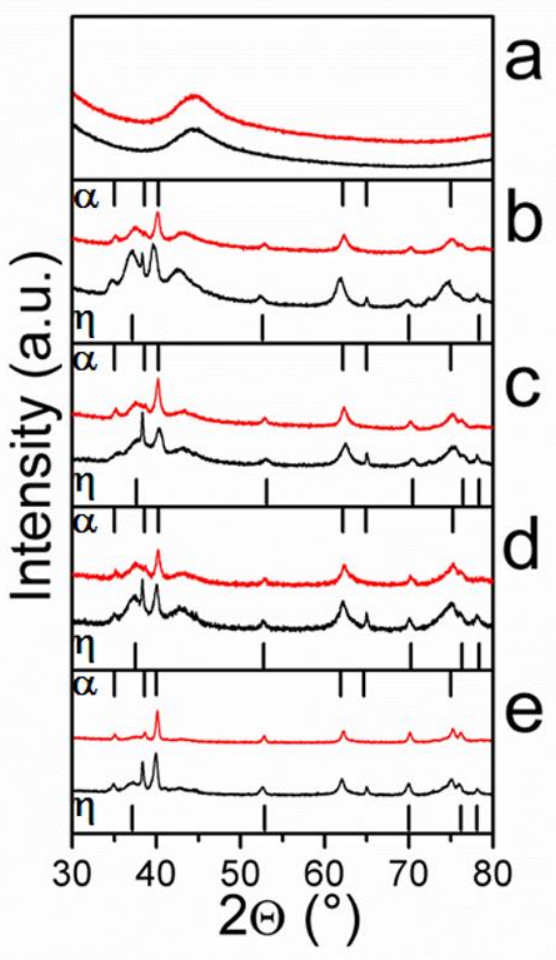

Figure 5. 


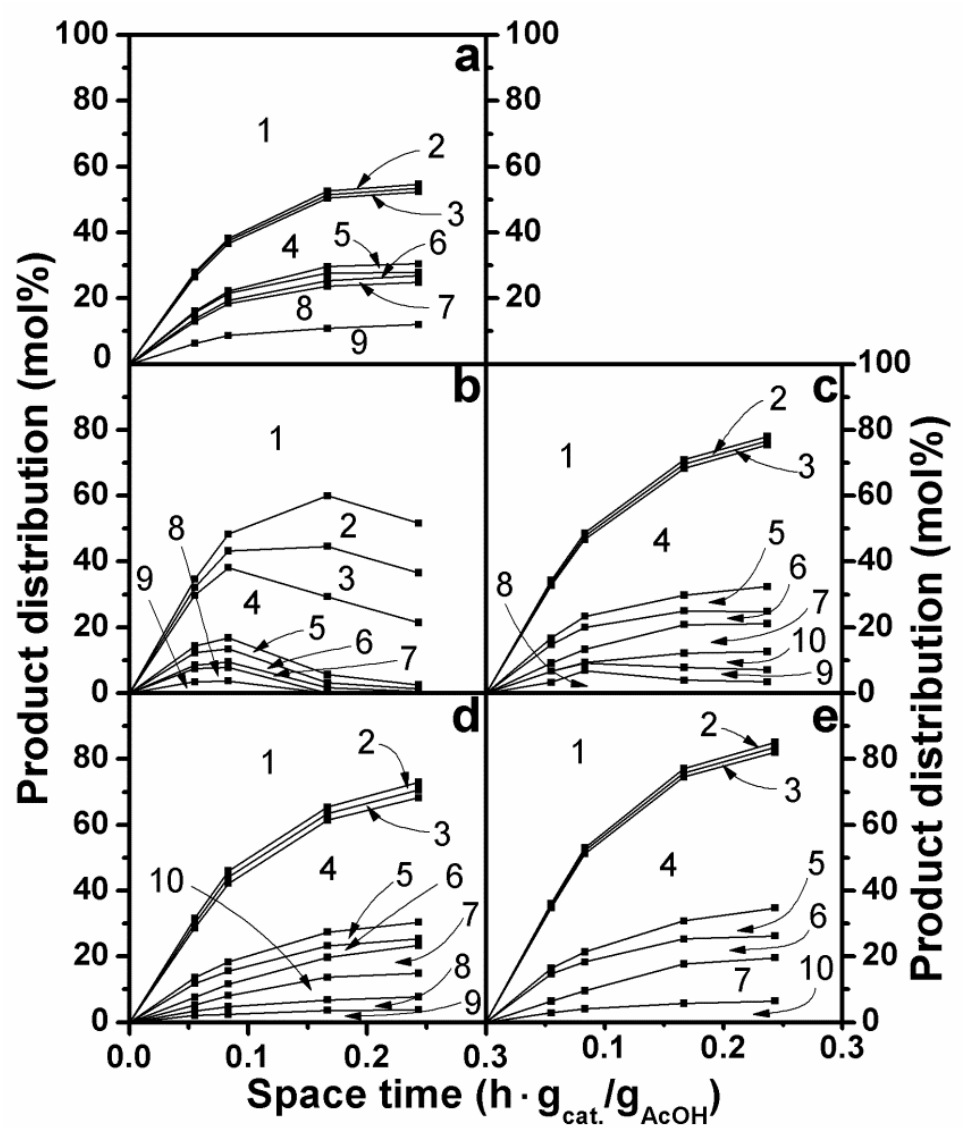

Figure 6.

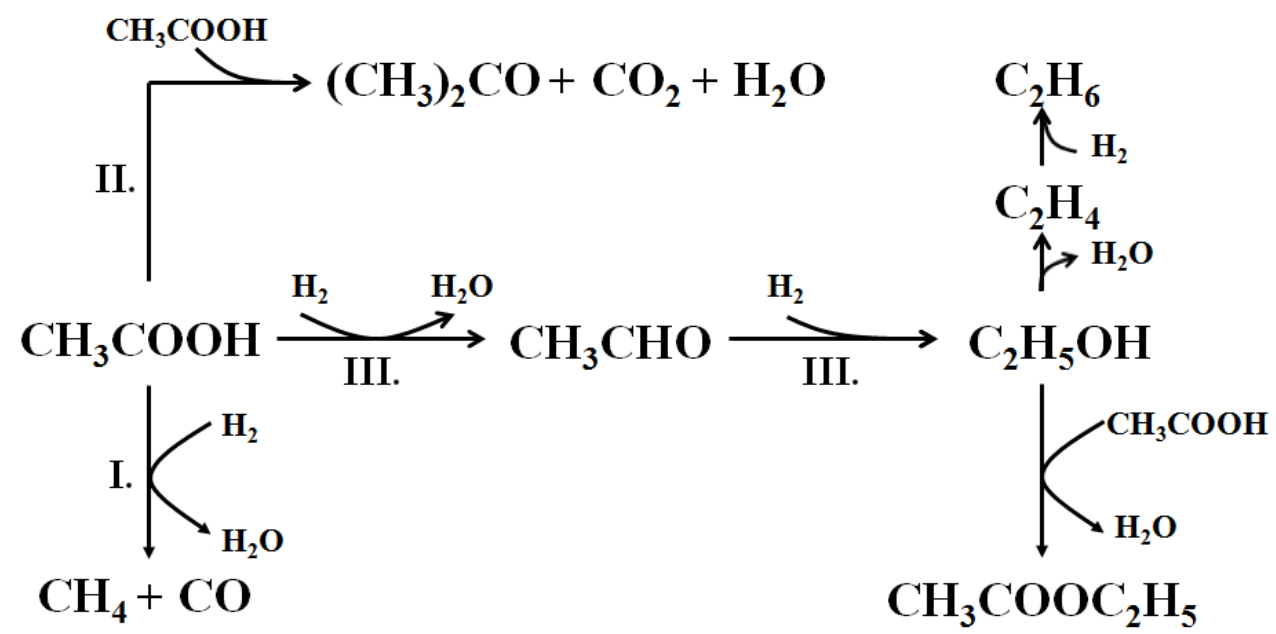

Figure 7. 

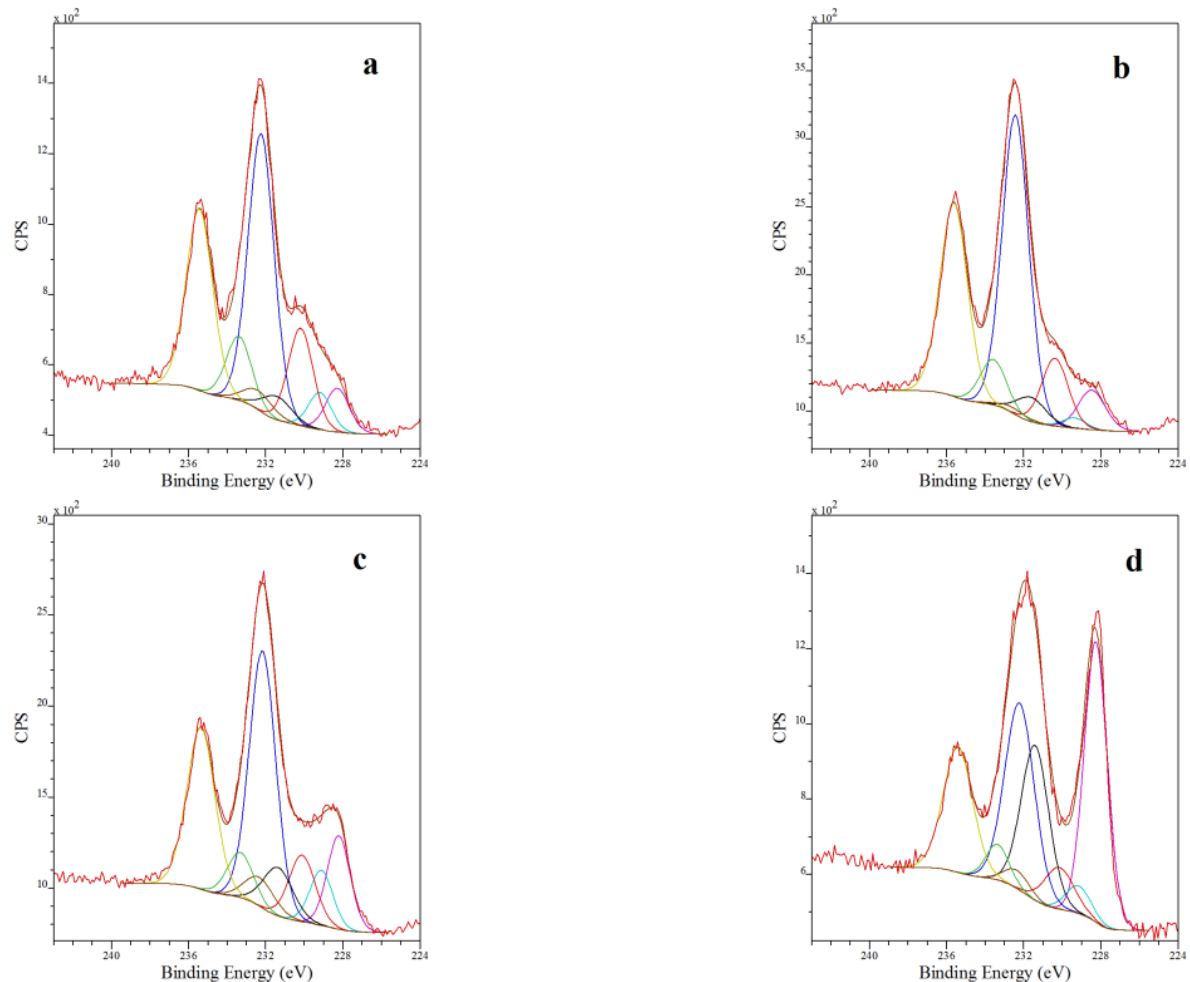

Figure 8. 